\title{
LA LENGUA ÁRABE A TRAVÉS DEL MANUSCRITO OSUNA, C. 587, D. 36-65 (1533-1539) DEL AHNSN*: ESTUDIO Y APORTACIONES HISTÓRICO-LINGÜÍSTICAS
}

\author{
Antonio Constán Nava**
}

\section{INTRODUCCIÓN}

El primer objetivo que se marcó en el presente trabajo fue la traducción al español de los textos en árabe del manuscrito OSUNA, C. 587, D. 36-65². La pista sobre este material fue dada por la Dra. Elia Gozálvez Esteve, quien había trabajado el documento para la realización de su Tesis doctoral: Análisis de un señorío valenciano: el Marquesado de Lombay, trabajo que aún permanece inédito ${ }^{2}$. Ella había expresado las dificultades de este texto bilingüe árabe-castellano/valenciano muy prometedor para el conocimiento de la lengua de estos moriscos. Una vez conseguida una copia del documento en diapositivas y, tras revisarlo en el Archivo Histórico Nacional, Sección Nobleza, fue planteado el objetivo, la pertinente traducción, objetivo primero que fue dando pie cada vez más a otras finalidades que podrían ampliar el sentido de la traducción, convirtiendo ésta

* Archivo Histórico Nacional, Sección Nobleza.

** Universidad La Manouba (Túnez).

1. Hay que señalar que este artículo ha sido extraído como resumen del trabajo La lengua árabe a través del manuscrito OSUNA, C. 587, D. 36-65 (1533-1539) del Archivo Histórico Nacional Sección Nobleza: Traducción, estudio y aportaciones histórico-lingüísticas, que ha sido posible gracias a la XXI Ayuda para la Investigación de Temas Mudéjares 2009 otorgada por el Centro de Estudios Mudéjares.

2. La Tesis doctoral completa permanece inédita, tal y como he apuntado anteriormente. Sin embargo, gracias al trabajo realizado sobre los manuscritos, tanto por parte de la Dra. Elia Gozálvez en la parte castellana de los manuscritos, como lo trabajado por mí, tendremos la suerte de ver publicado un trabajo aparte al presente, centrado en el estudio económico de los manuscritos, titulado Los vasallos moriscos del Marquesado de Llombai en época de Don Juan de Borja entre 1533 y 1539, Valencia, ed. Institució Alfons el Magnánim (en prensa), y al que iré remitiendo a lo largo de este artículo. 
en un objetivo más de los que se iban desarrollando, pues el manuscrito brindaba la ocasión de poner de relieve varias corrientes de investigación ${ }^{3}$.

De esta manera, lo que comenzó por ser un trabajo de traducción histórica, se ha ido transformando en una investigación que se ha querido articular en dos partes. La primera de ellas es el estudio lingüístico-interpretativo del documento, mientras la segunda parte es la trascripción y posterior traducción de los textos árabes de dicho documento, segunda parte que por espacio no será incluida en este artículo. Se procura continuar en el presente trabajo las corrientes historiográficas más recientes a la hora de estudiar una época en concreto, centrándose en la minoría morisca. A la vez, se intentará dar respuestas a algunas de las cuestiones abiertas que se plantean a la hora de tratar la situación lingüística de los moriscos valencianos en un lugar concreto y un espacio de tiempo acotado por la propia datación del documento, conclusiones siempre abiertas a revisiones posteriores que amplíen, sugieran, critiquen o concluyan las que aquí se aporten. No se pretenden aportar unas conclusiones definitivas, sino abrir un camino provisional de una investigación que, sabiendo de antemano limitada al tratarse de un tema concreto, el del estado sociolingüístico de la comunidad musulmana morisca del Marquesado de Llombai, se presenta aquí como una conclusión a la que se llega tras haberse formulado las hipótesis previas de trabajo.

Del estudio lingüístico se adelanta que será un estudio muy limitado, tanto en documentos como en lengua árabe, pues los legajos no son más que un mero control de jornales, unos "libros de cuentas" donde el escriba (en este caso suele serlo el alamín encargado de la aljama morisca ${ }^{4}$ ) anota los diferentes jornales (realizados como concepto de "tanda") que realizan los miembros de la comunidad musulmana del Marquesado de Llombai, concretamente Catadau y Aledua, muchas veces sin dar apenas datos sobre los mismos. Por lo tanto, el presente trabajo no tiene otra pretensión que la de ser una introducción al estudio histórico-lingüístico de una comunidad morisca concreta, como lo es la que habitó en el Marquesado de Llombai en un período de tiempo determinado (1533-1539), sabiendo de antemano las limitaciones que comporta una síntesis de este carácter, basada en un material escrito muy específico.

3. Cfr. prólogo a cargo de Francisco Franco Sánchez en E. GozÁlvez Esteve y A. Constán NAvA, op. cit.

4. M. RuZAFa GarCíA, «Señores cristianos y campesinos mudéjares en el País Valenciano (siglo XV)», Señorío y feudalismo en la Península Ibérica (ss. XII-XIX). Actas del coloquio celebrado en Zaragoza los días 11, 12, 13 y 14 de diciembre de 1989, en E. SARASA SÁNCHEZ y E. SERRANO MARTín (eds.), 1993, p. 428: “Un miembro elegido por la aljama o designado por el señor, el alamín, suele encargarse de recaudar rentas e impuestos, entregando su producto al señor". 


\section{El DOCUMENTO OSUNA, C. 587, D. 36-65 DEL AHNSN}

Antes de pasar a estudiar el documento, parece oportuno describir el mismo desde un punto de vista material y físico. El documento 587 del Archivo Histórico Nacional, Sección Nobleza ${ }^{5}$, concretamente los legajos correspondientes entre el 36 al 65 (el documento es más extenso en legajos, pero se limita aquí a los que contienen escritura en árabe, pues el resto del documento ya fue abordado por Elia Gozálvez en su Tesis Doctoral defendida en la Universidad de Alicante el día 17 de diciembre de $1990^{6}$ ). Se trata de un documento bilingüe, escrito en árabe y castellano/valenciano (más adelante se tratará el tema de las lenguas utilizadas) por varias manos. El documento se encuentra en el AHNSN, perteneciente al archivo de los Duques de Osuna. Está dividido en varios legajos entre los que se encuentran los que aquí se estudian. El documento OSUNA, C. 587, D. 36-65 consta de noventa folios, de los que cincuenta y cinco están escritos, en su mayor parte, en árabe o tienen alguna frase en árabe.

A continuación se describe físicamente el documento, detallándose algunos elementos que pueden ser útiles para su posterior estudio.

En la portada del documento figura la inscripción: “Cuentas, cartas, recibos de las rentas del Marquesado de Llombai en tiempo de Moriscos con firmas y notas en caracteres árabes".

\begin{tabular}{|c|c|c|}
\hline Lg. 587-36 & 1 folio & $\begin{array}{l}\text { La firma tiene una tinta más clara que el resto del } \\
\text { documento, pero mantiene la misma tonalidad. }\end{array}$ \\
\hline Lg. 587-36bis & 1 folio & \\
\hline Lg. 587-37 & 1 folio & Fecha de 10 de noviembre de 1533 \\
\hline Lg. 587-38 & 1 folio & \\
\hline Lg. 587-39 & 1 folio & \\
\hline Lg. 587-40 & 1 folio & Fecha de 7 de noviembre de 1534 \\
\hline & & $\begin{array}{l}\text { Por detrás del folio, en castellano, pone "albara de } \\
\text { mecli" }\end{array}$ \\
\hline Lg. 587-41 & 1 folio & Fecha de 17 de marzo de 1535 \\
\hline Lg. 587-42 & 1 folio & Fecha de 26 de junio de 1535 \\
\hline Lg. 587-43 & 1 folio & \\
\hline Lg. 587-44 & 1 folio & Fecha de 12 de enero de 1536 \\
\hline Lg. 587-45 & 1 folio & Fecha de 14 de enero de 1536 \\
\hline Lg. 587-46 & 1 folio & Fecha de 19 de enero de 1536 \\
\hline
\end{tabular}

5. A partir de ahora nombrado como AHNSN.

6. E. GozÁlvez Esteve y A. Constán NAva, op. cit. 
Lg. 587-47 1 folio

Lg. 587-48

Lg. 587-49

Lg. 587-50

Lg. 587-51

Lg. 587-52

Lg. 587-53

Lg. 587-54

Lg. 587-55
1 folio

1 folio

2 folios que:

${ }^{*}$ f. $1-9$ sccs.

* f. $2-7$ sccs.

6 folios que:

* f. $1-6$ sccs.

* f. 2 - 10 sccs.

* f. $3-9$ sccs.

* f. $4-10$ sccs.

*f. $5-9$ sccs.

${ }^{*}$ f. $6-3$ sccs.

8 folios que:

* f. $1-9$ sccs.

*f. $2-7$ sccs.

* f. $3-7$ sccs.

* f. $4-7$ sccs.

*f. $5-7$ sccs.

* f. $6-5$ sccs.

${ }^{*}$ f. $7-6$ sccs.

* f. $8-2$ sccs.

2 folios que:

* f. $1-4$ sccs.

${ }^{*}$ f. $2-6$ sccs.

1 folio, 5 sccs.

8 folios que:

* f. $1-7$ sccs.

*f. $2-7$ sccs.
La tinta utilizada por el escriba árabe es de otro color (roja) a la utilizada por el escriba castellano (negra).

Fecha de 25 de enero de 1536

La tinta utilizada por el escriba árabe es de otro color (negra) a la utilizada por el escriba castellano (roja).

Fecha de 28 de julio de 1536

Dos tintas diferentes:

- Letras árabes en tono negro

- Letras castellanas en todo rojizo

Las cantidades escritas en caracteres árabes están escritas con la misma tinta que las letras castellanas; y las cantidades escritas en símbolos latinos están escritas con la misma tinta que las letras en castellano.

Fecha de 1534

En ambos textos (árabe y castellano)

se ha empleado la misma tinta.

En este legajo, la escritura en árabe está realizada con tinta negra, mientras que la escritura en castellano se ha realizado con tinta roja.

Fecha de 2 de enero de 1537

Se ha utilizado la misma tinta para ambos tipos de escritura.

Este legajo corresponde a la parte trasera del lg. 587-54.

Se han utilizado dos tipos de tintas diferentes: en la escritura árabe tiene un tono negro y en la escritura castellana, el tono es rojizo. 


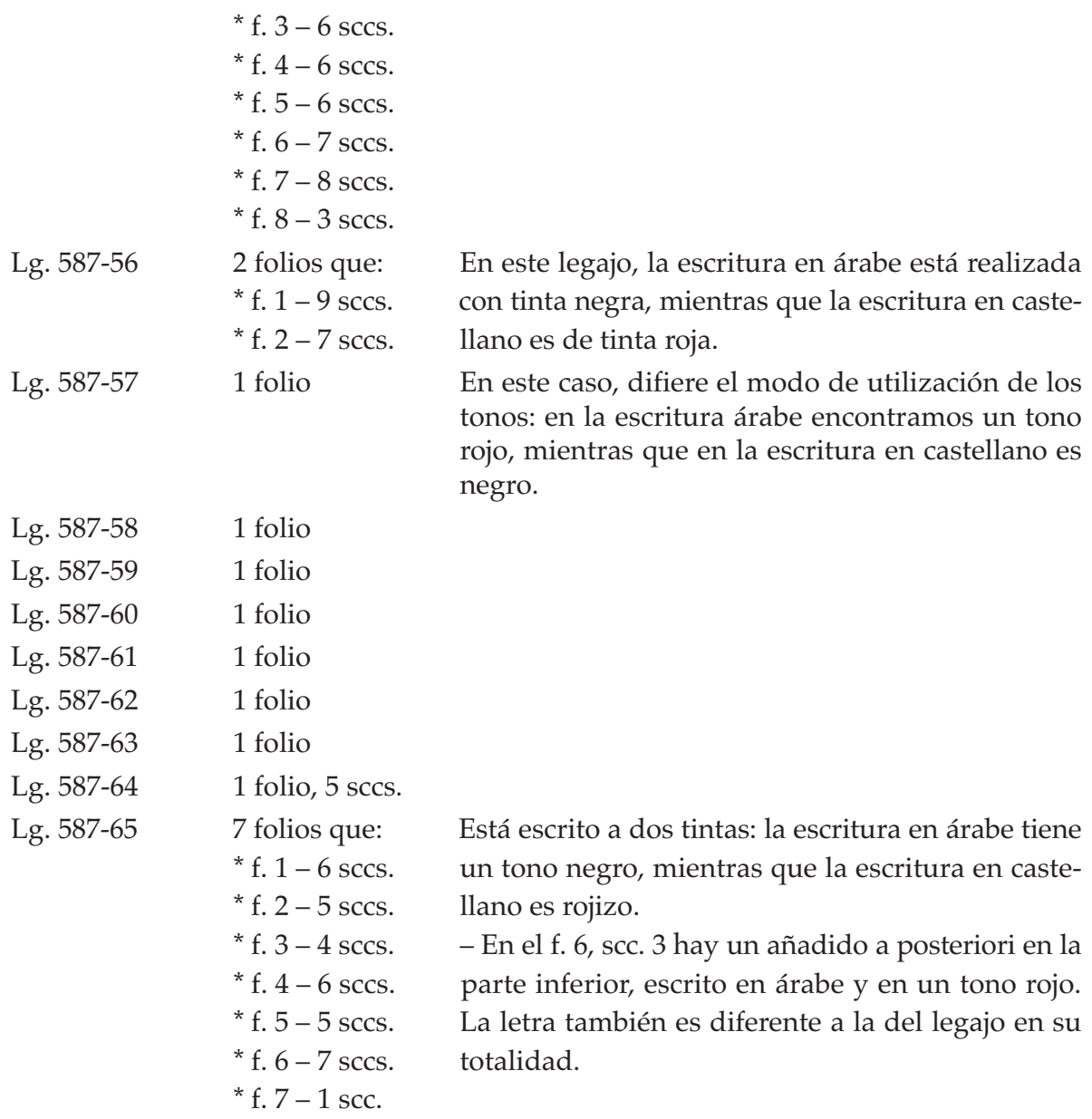

La cronología de los textos comprende desde 1533 hasta 1539. El contenido de los documentos, según la descripción que el propio AHNSN hace de él, refiere las cuentas, recibos y cartas del Marquesado de Llombai (con firmas y notas árabes). Tras el estudio, se puede asegurar que el contenido de los legajos se divide en dos tipos:

1 / Un primer tipo o grupo, el que comprende los lgs. 587-36 al 587-45, lgs. 587-48 al 587-49 y lgs. 587-58 al 587-64, que están escritos en castellano para el señor cristiano, por mano del baile, en los que se plasma un recibo de pago o entrega de sueldos, carta siempre cotejada con la firma del representante de la comunidad morisca; a veces es un comentario breve que detalla cantidades, otras es simplemente una firma o una certificación de que lo escrito en castellano es cierto y el escriba en árabe da fe de ello. De entre todos los legajos, son estos lo que menos impor- 
tancia tienen a nivel lingüístico, a pesar de ser los legajos en los que más manos escriben en árabe, dado que se trata de firmas o visos.

2 / Un segundo grupo, formado por los lgs. 587-46 al 587-47, lgs. 587-50 al 587-57 y el lg. 587-65. Estos legajos responden claramente a las cuentas, un registro o relación de los jornales realizados en concepto de tandas que los miembros de la comunidad morisca realizaban como pago a su señor. Son legajos bilingües divididos a su vez en tres grupos:

a. los escritos en árabe y en castellano

b. los escritos en árabe y en valenciano

c. los escritos en árabe, y en castellano y valenciano conjuntamente.

Su ordenación seguirá la estipulada en el AHNSN, a pesar de que se podrían ordenar: primero, por el lugar geográfico en el que se sitúan los distintos legajos (Aledua, Llombai, Catadau) y, dentro de este orden geográfico, por fechas; o segundo, por cronología (ya que no siempre será está la característica elegida para su ordenación). De esta manera, los legajos han sido ordenados, principalmente, de modo cronológico. Formalmente se ha seguido el patrón de ir traduciendo cada legajo por partes. La diferencia a la ordenación establecida en el AHNSN radica en que aquella está dispuesta a la manera latina, es decir, aquella que prima en primer lugar la izquierda sobre la derecha y su lectura en idéntico orden, mientras que para el trabajo se ha optado, respetando este orden, por hacer la traducción como en realidad debería ser su orden, es decir, siguiendo una ordenación de estilo oriental, aquella que prima la derecha por la izquierda. Esta decisión viene dada después de comprobar que el original en sí, en su mayoría, sigue las pautas de ordenación oriental: la primera página de un legajo siempre es la última (según la concepción oriental) y siempre es leída de derecha a izquierda y nunca al revés. De este modo, cada folio estará dividido en secciones que, dependiendo de un legajo u otro, estarán mejor o peor delimitados. Así, por ejemplo en los legajos 587-51, 587-53 y otros más, existe una separación con líneas horizontales que delimita los distintos campos o secciones. Empezando por el margen superior derecho, se irá procediendo a su lectura hacia abajo, para luego continuar en la columna delimitada, por su parte superior izquierda hasta el final. Así, la sección 1 de un folio de un legajo concreto será el primer campo correspondiente a la parte superior derecha del folio $(\mathrm{o}$, como ocurre en algunos casos, el encabezado del folio).

\section{El MARQUeSADO DE LlOMBAI Y LOS MORISCOS}

El material sobre el que se ha basado el estudio está limitado geográficamente, pues pertenece a una zona concreta de la geografía valenciana: Llombai, Catadau y Aledua. Por lo tanto, y como se verá en el análisis posterior, no se ha podido establecer un análisis pormenorizado de la lengua árabe en el conjunto de la zona debido a la limitación implícita del documento pues pertenece a 


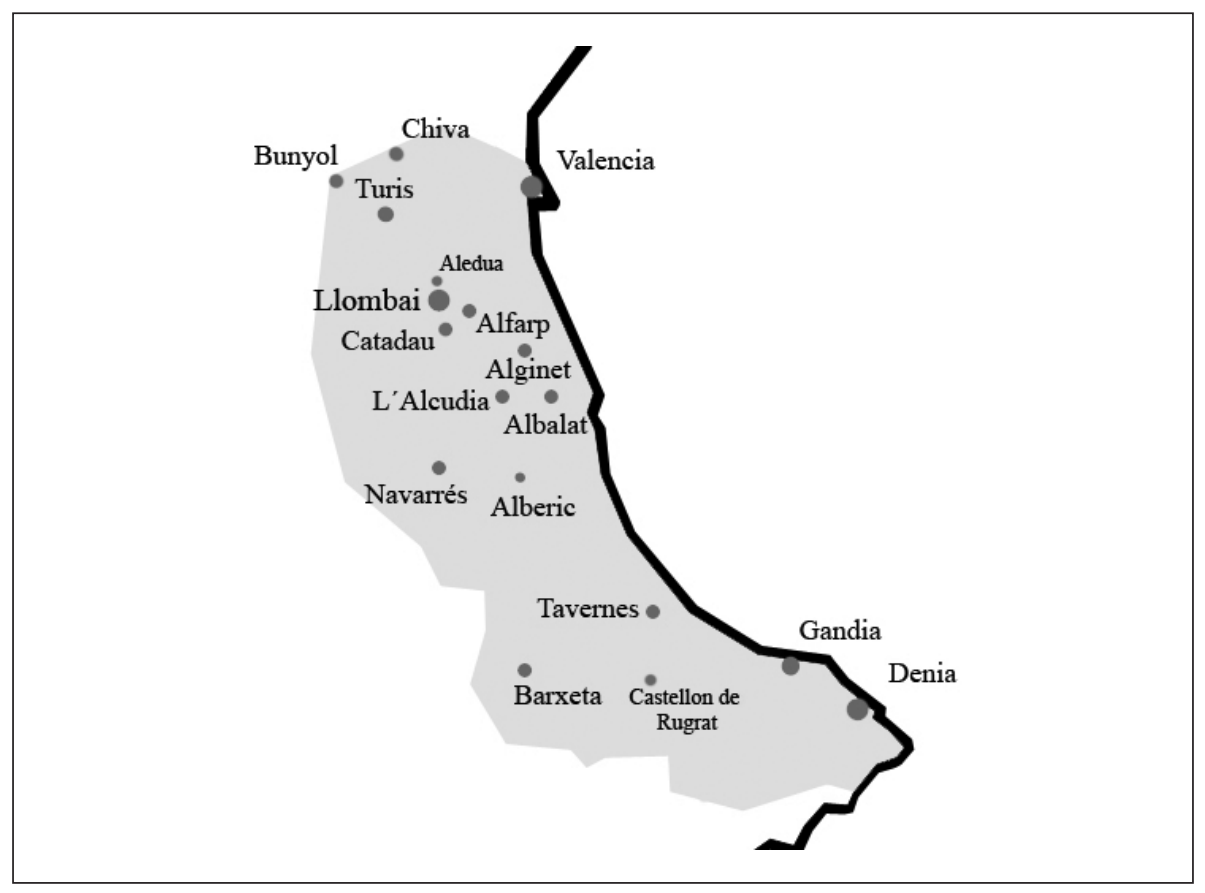

una zona específica ${ }^{7}$. Aun así, y extraído el marco de influencia geográfica por los viajes que se realizan en diferentes tandas, se ha podido establecer el marco geográfico por donde se mueven los jornaleros moriscos.

El municipio que ocupa es Llombai, por ser la población que da nombre al Marquesado al cual pertenecen los manuscritos. Se sitúa al sudeste de la Ribera Alta, a ambas partes del río Magro, entre la Sierra de Falquera y el macizo del Caroig. Su término municipal actual linda: al norte, con Picassent, Real de Montroi y Montserrat de Alcalá; al sur, con Alfarp y Catadau; y al oeste, con Dosaigües. Su altitud sobre el nivel del mar es de 99,5 m, mientras que el Collado de Buscarró, situado en su término, se eleva hasta los $653 \mathrm{~m}$ sobre el nivel del mar. Llombai dista $29 \mathrm{~km}$ de Valencia hacia el interior. En la época que se está analizando, Llombai se situaba en un área eminentemente señorial y mudéjar, destacando su población mixta: cristiana y musulmana.

Los textos hablan de unas zonas en concreto, lugares donde se realizan los jornales, las idas y venidas de los trabajadores. En el mapa anterior se puede ob-

7. Un trabajo magnífico, recientemente publicado, que trata este tema en extensión, ha sido el de C. BARCEló y A. LABARTA, Archivos moriscos. Textos árabes de la minoría islámica valenciana 14011608, Valencia, Universidad de Valencia, 2009. 
servar la zona de influencia de estos viajes; en su mayoría viajes para transporte de mercancías (como se verá más adelante), de correspondencia (llevar albaranes) y, en menor medida, para acompañar a los altos cargos cristianos.

Llombai forma la "foia", junto con las poblaciones de Alfarp, Catadau y Aledua $^{8}$, lo que en su día se conoció como la baronía de Llombai, que tuvo su origen en el reparto de las tierras conquistadas por Jaime I entre sus caballeros ${ }^{\text {. }}$ No será hasta que Aymerich de Centelles, a través de posteriores donaciones, herencias y ventas, consiga que dichos lugares fueran unificados jurisdiccionalmente ${ }^{10}$. A finales del siglo XV se logró la unidad territorial tras sucesivas ventas y compras por parte de sus dueños: "El fet més sobresortint, però, és l'enorme deute censal que van acumular" sus señores, los Centelles, "que els va obligar [...] a vendre la foia a Francesc Vives" en $1478^{11}$. En el contrato de venta se estipuló que los antiguos dueños podían recuperar las tierras durante los dos años siguientes en el caso de subsanar la deuda censal que habían contraído, pero antes de que esto ocurriese, el propio Francesc Vives de Boïl, señor de Bétera, vendía "la foia de Llombai al cardenal i bisbe de València Roderic de Borja amb les mateixes condiciones de la compra feta als Centelles"12. Será el hijo de éste, Juan de Borja I quien anexionó los territorios a la Casa Ducal de Gandía, logrando de esta manera la unidad territorial. En 1530 Carlos V “concedió a Don Francisco de Borja el título de Marqués de Llombai, quedando en esa fecha constituido el Marquesado de Llombai" ${ }^{\prime 3}$.

La situación de vencidos de los mudéjares en relación con la de los cristianos hizo que aquellos tuvieran un emplazamiento definido para tal situación de vencidos ${ }^{14}$ : de esta manera se constituía Llombai como centro administrativo, político y comercial, habitado por los vencedores cristianos viejos y, también, por un núcleo de habitantes musulmanes; centro administrativo alrededor del

8. Para más información sobre esta población, cfr. E. GOZÁLBEZ ESTEVE, «Crónica del fracaso de una repoblación: Alédua», Actes de la VI Assemblea d'Història de la Ribera, vol. II, 1998, pp. 41-60.

9. E. GoZÁlbez ESTEVE, «Señores y señoríos: aspectos sociales y económicos», Revista de Historia Moderna, 24, 2006, p. 68. La autora cita: AHN: Sección Osuna, Leg. 722-659, año 1238, 28 julio. Asedio a Valencia: va inserto en un traslado de 1259. A. FERRANDO y FrANCÉs, Llibre del Repartiment del Regne de Valencia, n ${ }^{\circ} 2238-549$ Lombay y Catadau. No 325-2225, Alfarpe. N$^{\circ} 2208$ (año 1237) Aledua, no 1099 (año 1239) Aledua.

10. E. GozÁlbez EsteVE, «Señores y señoríos...», p. 68. Para una información más detallada sobre la formación de la baronía de Llombai, cfr. M. ARDIT, Creixement econòmic i conflicte social. La foia de Llombai entre els segles XIII $i$ XIX, Catarroja-Barcelona, Afers, 2004, especialmente las pp. 19-28.

11. M. ARDIT, op. cit., p. 28.

12. Ibídem, p. 31.

13. E. GozÁlbez EsteVE, «Señores y señoríos...», p. 68. Además, para más detalles sobre los sucesos, cfr. M. ARDIT, op. cit., concretamente las pp. 28-37.

14. E. GozÁlbez Esteve, «Cristianos, mudéjares y moriscos en el marquesado de Llombai», Revista de Historia Moderna, 17, 1998-1999, p. 196. En nota 2, la autora cita: T. HALPERIN DoNGHI, Un conflicto nacional. Moriscos y cristianos viejos en Valencia, Valencia, Institución Alfonso el Magnánimo, 1980, pp. 52-54. 
cual giraban los lugares de Catadau, Alfarp y Aledua, con una población exclusivamente mudéjar ${ }^{15}$.

Esta realidad habla de una coexistencia en mayor o menor medida de ambas comunidades: "En Llombai el escaso número de habitantes no fue un impedimento para que la universidad cristiana y la aljama mudéjar, más tarde morisca, compartieran un mismo espacio geográfico, aunque con diferente realidad socio-económica"1 ${ }^{16}$. En esta coexistencia, dejando de lado los altibajos socioeconómicos entre ambas comunidades, podemos decir que, obviamente, hubo similitud, aunque con diferentes intereses, razón más que contundente que contribuyó a su distanciamiento.

Por su lado, el duque de Gandía se mostraba ajeno e indiferente a la dualidad entre estos dos pueblos, más interesado y preocupado en conservar, y en muchos momentos en recuperar su patrimonio, que en intervenir en una compleja red social, la cual, en muchos aspectos, le era ventajosa ${ }^{17}$.

En el documento aparecen nombradas varias personalidades cristianas. Entre ellas, el baile. Durante los siglos XVI y XVII el marquesado sólo tenía un baile, el cual residía en Llombai, acumulando en su persona algunas funciones por delegación del propio procurador general o "por la fuerza de la costumbre" $^{18}$. La función más específica del baile era la de ser "juez de todas las cuestiones suscitadas en torno a la explotación económica" del marquesado. Además, era el responsable de la gestión judicial concerniente a los moriscos ${ }^{19}$. En la época del documento, el baile de Llombai era Gabriel de Llanos. Como se podrá ver en los textos analizados, en los legajos del segundo grupo, sólo el TA ${ }^{20}$ da referencias a este personaje, mientras que el TC nunca lo nombra; sin embargo, en los legajos del primer grupo, sí aparece la persona del baile pues será el mismo el que escriba varios de los legajos. E. Gozálvez Esteve sostiene que no siempre este baile ejerció su oficio con la profesionalidad que le era

15. E. GozÁlvez Esteve, «Señores y señoríos...», p. 68. Cfr. E. GozÁlvez Esteve y A. Constán NAVA, op. cit., especialmente el capítulo II.

16. Ibídem, p. 68: en el artículo de E. GozÁlvEZ, «Cristianos, mudéjares y moriscos...», dice en la p. 168 que los diferentes intereses de cada comunidad contribuyeron al posterior distanciamiento de ambas comunidades.

17. E. GOZÁLVEZ ESTEVE, «Señores y señoríos...», pp. 68-69.

18. Ibídem, p. 198.

19. Ibídem, p. 198. Para conocer más sobre las funciones del baile, nos remitimos a la obra de carácter general de L. PILEs Ros, Estudio documental sobre el bayle general de Valencia, su autoridad y jurisdicción, Valencia, Institución Alfonso el Magnánimo, 1970. Entre algunas de sus características destacamos: 1. La titularidad; 2 . La duración de la concesión del cargo; 3. La base territorial sobre la que ejercía su jurisdicción; 4 . El número de causas y asuntos que de ordinario podía conocer dentro de su campo de atribuciones; y 5. La subdelegación por su parte del oficio siempre y cuando existiesen motivos razonables (Cfr. J. Vicente CAbezuelo Pliego, La curia de la procuración. Estructura de una magistratura medieval valenciana, Alicante, Instituto de Cultura "Juan Gil-Albert", 1998, pp. 34-35).

20. $\mathrm{TA}=$ texto árabe; $\mathrm{TC}=$ texto castellano/valenciano. 
exigida: "A mediados del siglo XVI el arrendatario acusa al baile Gabriel de Llanos de tener muchos descuidos"

La comunidad musulmana del Marquesado de Llombai estaba representada por la aljama, organismo social-político-religioso, único portavoz válido ante el señor cristiano, primero a través de la figura del alfaquí para interponer las reivindicaciones de los mudéjares; y, más tarde, a través de la figura del alamín que, tras la conversión, será la única válida como representante ante el señor (además del consejo de viejos), al desaparecer la figura del alfaquí dada su función religiosa. El alamín era el principal administrador de cada aljama ${ }^{22}$, cargo que en los documentos se encuentra en la persona de Miquel Pilli. El alamín presidía el consejo local y la rutina diaria de la comunidad y, aunque era el garante de la misma, no por ello dejaba de ser un excelente aliado y auxiliar del señor, el marqués de Llombai Francisco de Borja, que hasta la muerte de su padre el 8 de enero de 1543, no obtendrá el título de IV duque de Gandía ${ }^{23}$. De este modo, en los textos aparece continuamente referida la persona del duque, en este caso, Juan de Borja y Enríquez, padre de Francisco de Borja. Por otro lado, en las relaciones del monarca con la capital valenciana es clave la figura del racional ${ }^{24}$, figura que aparece nombrada repetidas veces a lo largo de todo el documento como Joan Garsía $^{25}$. Será en 1535 cuando, tras el trienio cumplido por el anterior racional, Nicolau Benet Dalpont, se proceda a la elección del nuevo racional, recayendo el cargo en la persona de Joan Garsía, quien ejerció el cargo hasta 1542 y falleció en $1547^{26}$.

\section{LA LENGUA}

¿Qué es una lengua? Para la Real Academia Española de la Lengua: “(Del lat. lingua): 1. f. Sistema de comunicación verbal y casi siempre escrito, propio de una comunidad humana; 2. f. Sistema lingüístico cuyos hablantes reconocen modelos de buena expresión; 3. f. Sistema lingüístico considerado en su estructura; 4. f. Vocabulario y gramática propios y característicos de una época, de un escritor o de un grupo social" 27 .

21. E. GozÁlvez EsteVE, «Cristianos, mudéjares y moriscos...», p. 198.

22. Ibídem, pp. 198-199.

23. J. MARTí FerRANDO, Instituciones y sociedad valencianas en el Imperio de Carlos V, Valencia, Biblioteca Valenciana, 2002, p. 145.

24. Ibídem, p. 176, para el que la misión de Joan Garsía como hombre del rey en el ayuntamiento “indicaba que esa posición, en última instancia, se hallaba presionado por la autoridad del municipio, del cual había sido extraído, y por la autoridad del monarca, que en definitiva era quien le había ratificado en su puesto".

25. Aparece un total de 20 veces a lo largo de todo el documento OSUNA, C. 587, D. 36-65 del AHN, SN.

26. J. MARTí FERRANDO, op. cit., pp. 169-175.

27. RAE, 1992, $21^{\text {a }}$ ed. digital. 
La lengua hablada por los mudéjares y moriscos, la lengua árabe en su variante andalusí, se acoge perfectamente a los cuatro estadios definidos por la RAE. La lengua es el enlace fundamental entre los individuos de una misma comunidad, en palabras de L.F. Bernabé y M. a J. Rubiera, la lengua "resulta la base fundamental para la expresión, digamos oficial de cualquier comunidad" 28 . Uno de los aspectos más controvertidos e investigados de la época es el que tiene que ver con esta situación lingüística, primero, de los mudéjares y, más tarde, de los moriscos.

Sobre la lengua hablada por mudéjares y moriscos se han acuñado dos términos: algarabía y aljamía:

"«Algaravía» $y$ «Algemía» son las dos únicas denominaciones lingüísticas que vemos usar en la documentación durante todo el siglo XVI para referirse a la lengua de los moriscos o cristianos nuevos y a la lengua romance de los cristianos viejos, normalmente valenciano/ catalán, pero que también podía extenderse en su uso al castellano [...] En tan tardía fecha como 1599 algunas declaraciones testificales diferencian con claridad cómo es su nombre en algarabía y cómo en algemía [...] Algunos moriscos firman, escriben y leen en algarabía [...] Los comerciantes y los síndicos o clavarios de la aljama llevan su contabilidad o registros en árabe. Precisamente estos conocimientos les convierten en peritos capaces de leer e interpretar un albarán falso escrito en algarabía en una denuncia por estafa. Otros saben firmar en romance o incluso escribir en valenciano" ${ }^{29}$.

Por otro lado "cabe la posibilidad de que con la conversión forzosa del siglo XVI y la política de asimilación religiosa y cultural, los moriscos se encerrasen en sí mismos, rehuyesen la convivencia con los cristianos, se reafirmasen en sus propios caracteres culturales, intensificaran su fe en el Islam, abo-

28. L.F. Bernabé POnS y M. a J. Rubiera Mata, «La lengua de mudéjares y moriscos. Estado de la cuestión», VII Simposio Internacional de Mudejarismo. Teruel, 19-21 de septiembre de 1996. Actas, Teruel, Centro de Estudios Mudéjares, 1999, p. 608.

29. E. Císcar PAllarés, «"Algaravía" e "algemía”. Precisiones sobre la lengua de los moriscos del Reino de Valencia», Al-Qanțara, Madrid, XV/1, 1994, pp. 138-139, cita en p. 138: A. FERRANDO FRANCÉs, Consciencia idiomática i nacional dels valencians, València, 1980 quien advierte que la expresión algemia o aljamia, como romance, se impone a partir del siglo XV frente a algaravia o morisc como forma de evitar, a su juicio, la denominación de catalán. Según R.I. Burns, la expresión "algaravía" procedería de "algarbi", y "aljamía" de "al-agamiya", palabra que sólo al final de la época mudéjar empezó a ser utilizada como expresión de lengua o literatura románica escrita en caracteres árabes, literatura aljamiada. Para evitar las confusiones, se utiliza en este trabajo la forma de "algemia", tal como aparece en la documentación, como denominación de la lengua de los cristianos viejos; referente a la producción escrita o aljamiado, $c f r$. L.F. Bernabé Pons y M. ${ }^{a}$ J. Rubiera MATA, op. cit., p. 608 en nota 29 dice que "existe, evidentemente, una vacilación terminológica a la hora de utilizar este término para referirse a la producción literaria de mudéjares y moriscos 'Aljamía' o 'aljamiado' designa una realidad lingüística no-árabe, por lo que, en principio, cualquier escrito en castellano es un texto aljamiado para un arabohablante. Sin embargo, se ha utilizado el apelativo 'aljamiado-morisco' para referirse solamente a los textos escritos en castellano con grafía árabe, aun cuando existe un número de producciones mudéjares y moriscas escritas con grafía latina y, evidentemente, también en árabe". 
rreciesen la cultura de los cristianos y por tanto disminuyese el conocimiento y el uso de la algemia" ${ }^{30}$. No se puede pensar que esto fuese así, por lo menos en base a este manuscrito que, como se verá, existen razones de peso en contra de esta posible postura, dándose la circunstancia de que el bilingüismo estaba demasiado extendido en la comunidad morisca del Marquesado de Llombai. Que hubiese reacción anticristiana, no se pone en duda, pero quizá no iba en relación a no conocer la lengua de los cristianos pues, si esto hubiese sido así, cuando en el siglo XVI se comenzó con la represión por parte de la Inquisición en tierras valencianas contra el uso de la lengua árabe, esta reacción hubiese derivado simplemente en más presión y persecución contra los moriscos en el caso de que estos se limitasen sólo a hablar en árabe, y estos textos, manejados tanto por la personalidad cristiana como por el responsable de la aljama, dan el ejemplo de todo lo contrario.

También la propia realidad pone de relieve un bilingüismo ${ }^{31}$ muy extendido entre la lengua árabe (su variante andalusí) y el castellano o valenciano (algemia) de los cristianos de la zona valenciana ${ }^{32}$ : "En conjunto, la impresión global que se deduce de la lectura de los procesos anteriores a 1609 es que la lengua no es un 'problema', que, utilizando la expresión de R.I. Burns, no supone a fines del siglo XVI ninguna 'muralla', que existe una abundante, amplia y fluida comunicabilidad lingüística entre las dos comunidades" ${ }^{\prime 33}$. Además, existen datos de que muchos de ellos entendían y hablaban perfectamente el castellano pues "los consellers agermanados propusieron en el Consell General de 4 de diciembre de 1520 que se obligase a todos los mudéjares del Reino a llevar señales distintivas de su condición, porque muchos de ellos no llegaban a ser reconocidos por los cristianos a causa de que van ataviats y ben vestits y parlen molt clar, axí com si fossen crestians, y de ello podrían seguirse algunes coses en menyspreu de la ley y fe cristiana" 34 . Sin embargo, otros datos apuntan lo contrario, infor-

30. E. Císcar Pallarés, op. cit., p. 157.

31. C. Barceló Torres, Minorías islámicas en el País Valenciano. Historia y dialecto. Valencia, Universidad de Valencia e Instituto Hispano-Árabe de Cultura, 1984, cita a Ninyoles: "no hay cambio lingüístico sin bilingüismo" y que "las motivaciones básicas para aprender el segundo idioma pueden ser «instrumentales», por necesidad de intercomunicación o «integradoras», con propósito de incorporarse a otro grupo social y lingüístico".

32. Aunque son necesarios más estudios para conocer a partir de cuándo un morisco es llamado “aljamiado" por las autoridades cristianas. Cfr. L.F. Bernabé POnS y M. a J. Rubiera Mata, op. cit., p. 604.

33. E. CísCAR PALlARÉs, op. cit., p. 150. Ver los diferentes ejemplos documentados que el autor expone sobre esta idea. El autor llega a la conclusión de que muchos cristianos viejos entendían y hablaban la algarabía y viceversa, casi siempre, todos varones. Sin embargo, no se puede afirmar lo mismo en el caso del nivel de alfabetización de aquellos que, siendo cristianos viejos pudieran leer en lengua árabe ni viceversa, pues si hemos de reafirmarnos en que los escribas moriscos del documento utilizan el recurso del eufemismo para evitar "lecturas" que traigan complicaciones.

34. V.J. VAllés BorRÁs, La germanía, Valencia, Institució Alfons el Magnánim, 2000, p. 258. 
mando que el romance no estaba muy extendido entre los musulmanes valencianos tras la conversión forzada: "En unas ordenanzas del arzobispo de Valencia Jorge de Austria (1538-1544) se dan normas para que, en el sacramento de la Penitencia, les baste a los cristianos nuevos con 'nomenar sols lo nom de Iesús'”'35.

Hoy se sabe que el árabe de Valencia era uno de los dialectos del hispanoárabe ${ }^{36}$ y se puede mantener, que la población musulmana que vivía en el reino de Aragón había sufrido un proceso de adaptación lingüística menos agresiva que la sufrida en Castilla o en Granada ${ }^{37}$. La mayoría de los estudios sobre la cuestión de la lengua de los moriscos en la zona valenciana ha demostrado, básicamente, la pervivencia del uso del árabe, primero entre los mudéjares y, después, entre los moriscos valencianos hasta su expulsión en $1609^{38}$. No hay que olvidar que siempre que el estatuto de la comunidad musulmana fuese el de mudéjar, se les garantizaba el uso del árabe, mientras que no es así con el estatuto morisco, cuando se les está vedado su uso o se tiende a imponer políticamente su desaparición ${ }^{39}$. Esta dicotomía en el uso de la lengua tuvo mucho que ver con la actitud de la propia acción evangelizadora ejercida por parte de los cristianos a partir del siglo XV, primero en Granada y más tarde en Valencia, ya que esta situación de uso activo y pasivo de la lengua árabe por parte de los mudéjares y moriscos valencianos se convierte en una cuestión fundamental, reforzada por la actitud de los propios evangelizadores: unos propugnaban el acercamiento a los mudéjares y moriscos en su propia lengua árabe mientras que otros sostenían que éstos debían ser despojados de su lengua original como condición indispensable para su mejor instrucción religiosa en el cristianismo ${ }^{40}$. Otros autores llegan a plantearse si se trataba de bilingüismo o de diglosia: "podría tratarse de una dualidad en el uso de las dos lenguas, sin que se produjera el desplazamiento de una por otra hasta fines del siglo XVI, cuando la presión de los eclesiásticos y la Inquisición rompieron los límites de la intercomunicación de los dos grupos culturales, creando una situación conflictiva donde desde la conquista había habido otra globalmente estable" ${ }^{\prime 1}$. Lo que sí se ha probado ha sido el uso del árabe en el ámbito privado, una lengua "fuertemente arraigada entre los moriscos en fecha tardía y próxima a la expulsión, con un porcentaje

35. C. BArceló Torres, Minorías islámicas..., p. 148, cita a Robles, 1960, p. 379.

36. Ibidem, p. 161.

37. L.F. BERNABÉ PONS, «Aspectos lingüísticos árabes y religiosos islámicos en los estudios sobre mudéjares y moriscos (1975-2005)», X Simposio Internacional de Mudejarismo. Teruel, 14,15 y 16 de septiembre de 2005: 30 años de mudejarismo: memoria y futuro (1975-2005), Teruel, Centro de Estudios Mudéjares, 2008, pp. 297-329.

38. E. GUINOT, «Los mudéjares de la Valencia medieval: Renta y señorío», Áreas. Revista de Ciencias Sociales, 14, 1992, pp. 27-47, p. 31.

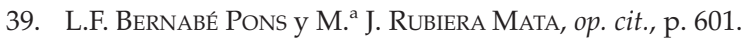

40. Ibídem, p. 601.

41. E. Císcar Pallarés, op. cit., p. 135. 
considerable de alfabetizados" ${ }^{\prime 2}$. Otra de las hipótesis defendidas es la existencia del árabe como lengua oficial de los mudéjares y moriscos hasta principios del siglo XVI y una situación de diglosia pasiva entre los moriscos varones ${ }^{43}$. Por otro lado, y sin entrar en esta materia, se podría ver qué grado de bilingüismo poseía la población cristiana en tierras valencianas, ya no en el binomio castellano-valenciano, sino con respecto de la lengua árabe ${ }^{44}$.

Sin ir más lejos en el tiempo, pues los textos que se tienen para este trabajo pertenecen al siglo XVI (concretamente, entre los años 1533 y 1539), no se va a profundizar más de la cuenta sobre qué lengua se hablaba en el momento de la conquista, pues no es materia del presente trabajo analizar esa cuestión que ya ha sido abordada en otros estudios por diferentes investigadores.

Lo que sí se puede afirmar es que, tras la conquista cristiana, el árabe sigue estando vigente en tierras valencianas y, lo que aquí interesa, en la zona objeto del presente estudio. Un mantenimiento que se produjo gracias a la situación geográfica en la que vivían los moriscos, lugares aislados y de difícil acceso, que les permitió mantener una cohesión interna de la comunidad musulmana, sobre todo gracias a la permanencia de la estructura de la aljama y al propio peso demográfico de la comunidad morisca y a la poca presencia cristiana ${ }^{45}$. Por otro lado, al igual que la zona granadina, "la zona valenciana fue una constante referencia para los moriscos aragoneses que habían perdido el árabe y mandaban allí a sus hijos a aprenderlo"46.

No se pondrán de manifiesto más que unas pequeñas aportaciones hipotéticas y, posiblemente, alguna solución respecto a la situación lingüística tras las Germanías, en un lugar concreto como lo es el Marquesado de Llombai, y dicho sea de paso, a partir de un exiguo aunque nada desdeñable corpus documental como el que ocupa el presente trabajo. En una primera impresión, los textos parecen estar escritos en una mezcla de lengua árabe con lengua aljamiada, pero, como se podrá comprobar tras el análisis lingüístico, no se puede defender decir que estos textos están escritos en lengua aljamiada. Para ello baste decir que algunas conclusiones que se verán más adelante se basan en las razones y características que Luis F. Bernabé y M. J Jesús Rubiera determinan a la hora de enfrentarse con textos de esta índole ${ }^{47}$. El trabajo intentará llegar a con-

42. Íbidem, pp. 135-136. Cita E. CísCar Pallarés, op. cit., p. 136: C. Barceló Torres, Minorías islámicas..., pp. 15-18 y 141-151. En el libro de M. DE EPALZA, Los moriscos antes y después de la expulsión, Madrid, 1992, hay alguna alusión al tema en pp. 90, 115 y 117.

43. C. BARCELó TORRES, op. cit., p. 121.

44. B. VINCENT, «Reflexión documentada sobre el uso del árabe y de las lenguas románicas en la España de los moriscos (ss. XVI-XVII)», Sharq Al-Ándalus, 10-11, 1993-1994, pp. 731-749.

45. L.F. Bernabé Pons y M. a J. Rubiera Mata, op. cit., p. 601. Además, gracias "al apoyo de algunos de sus señores cristianos".

46. Ibídem, p. 602. Los autores citan en nota 7: Domínguez Ortiz (1962).

47. Ibídem, pp. 610-617, especialmente las pp. 613 y 617, esta última en la que resumen las características dadas por otros investigadores. Además, cfr. Cfr. C. BARCELó y A. LABARTA, op. cit., 
clusiones generales del estado de la lengua árabe ya no tanto de la comunidad morisca de la zona valenciana que nos ocupa, sino la particular de los escribas, que no hacen sino reproducir la lengua única árabe dialectal que va dejando camino a la lengua romance imperante, sea ésta el castellano o el valenciano ${ }^{48}$.

\section{ESCRIBAS EN LENGUA CASTELLANA, ESCRIBAS EN LENGUA ÁRABE}

A lo largo del presente trabajo se ha podido corroborar que no siempre se encuentra la mano de un único escribano y una única escritura, ni en la parte donde la escritura es en castellano, ni donde la escritura es en valenciano y, sobre todo y lo que más interesa en aquí, en la escritura en árabe. Debido al poco margen temporal, pues los textos en árabe van desde el año 1534 al año 1538, sería osado establecer una posible diacronía de la lengua árabe en los textos estudiados, aunque se los pueda situar en una zona concreta, por lo que se estudiarán referidos a la lengua particular de una serie de escribanos. De aquí que haya sido necesario un estudio sobre los escribas en lengua árabe de los documentos y a la lengua empleada por estos a la hora de redactar.

Existen varios tipos de legajos: por un lado están aquellos escritos en castellano, en los que el apunte en árabe, o es una simple firma o es una pequeña frase que puntualiza en árabe lo que se dice en castellano, que intenta dar fe, corroborar o añadir una explicación simple de que lo dicho en castellano es válido y cierto ${ }^{49}$; por otro lado están los textos bilingües, en los que primero está escrita la parte en árabe y a su lado o debajo de aquel está el texto en castellano; y por último, los textos escritos en árabe y debajo de esta lengua se encuentra la aclaración o traducción en lengua valenciana.

Algunos de los interrogantes que se pueden extraer de este estudio previo son: ¿qué significa que, a veces, el traductor importante es el que escribe en castellano pero otras veces lo es el escriba árabe? ¿Hasta qué punto es el escriba árabe el traductor del castellano/valenciano o viceversa? ¿Es el mismo escriba para ambas lenguas o no? Y, por último, ¿qué contable trabaja a favor de la aljama y quién en contra? De todas estas cuestiones, el presente artículo intentará responder a las tres primeras, pues la última ha sido uno de los temas que se pueden encontrar en otro estudio ${ }^{50}$.

En los textos se distinguen hasta 11 escribanos diferentes en lengua árabe. De ellos, siete se pueden identificar con nombre, pues salen referidos como los propios firmantes o escribas de los textos. Véase a continuación los diferentes ejemplos de cada uno de los tipos de letras de los diferentes escribas:

p. 65: “Esa literatura aljamiada, característica y propia de Castilla y Aragón, es ajena a la tradición de la comunidad islámica valenciana".

48. L.F. Bernabé Pons y M. ${ }^{a}$ J. Rubiera Mata, op. cit., p. 618.

49. Cfr. Lg. 587-36, AHNSN.

50. Cfr. E. Gozálvez Esteve y A. Constán Nava, op. cit. y C. Barceló y A. Labarta, op. cit., p. 45. 
Tipo A

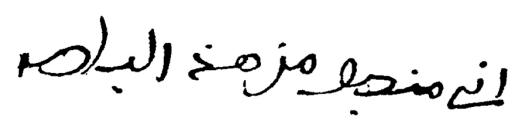

Tipo B isisisicis

Tipo C p)

Tipo D

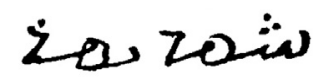

Tipo E

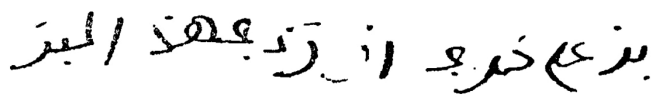

Tipo F

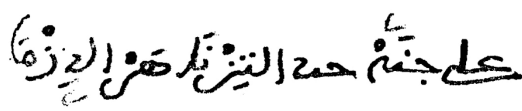

Tipo G

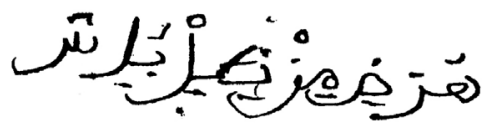

Tipo H

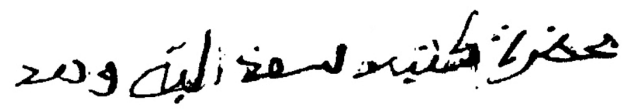

Tipo I

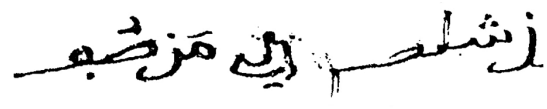

Tipo J

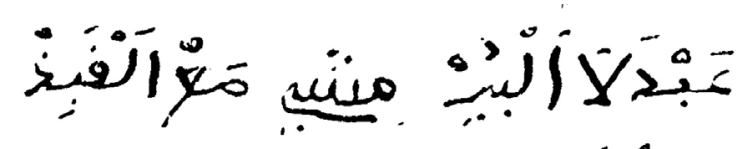

Tipo K

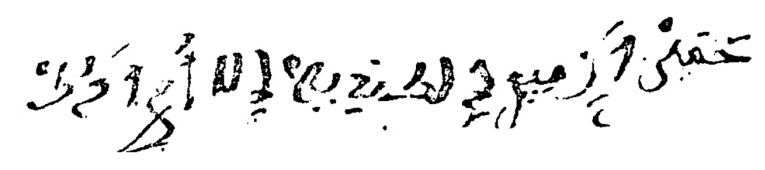


De los 11 tipos de letras, se puede decir que:
A - Miqel Pilli
مقل بلي
B - Ahmad Mecli
أحْمَذْ آَلْمِكِلنْ

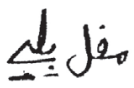

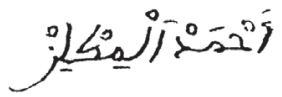
C - Juan Mecli
جون مقلي
D - Muhammad Leva
محمد لفا

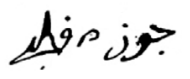
Wzes
E - Sin nombre
F - Sin nombre
NC
G - Abrahim Baboni

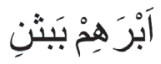
H - Sa`ad ibn Ahmad Babuni

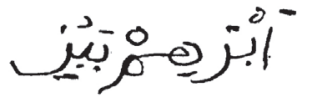

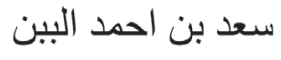
I - Juan Solas

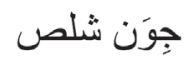
J - Sin nombre
NC

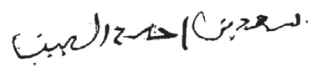

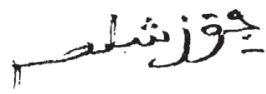
K - Sin nombre
NC

No todos los escribas tienen la misma cantidad de textos, ya que algunos de ellos, como el Tipo D, sólo firman con su nombre en una ocasión. Así pues, se distribuyen de la siguiente manera en cuanto a escritos:

Tipo A: 8 folios

Tipo D: 1 folio

Tipo G: 1 folio

Tipo J: 1 sección de 1 folio
Tipo B: 2 folios

Tipo E: 3 folios

Tipo H: 8 folios

Tipo K: 2 sccs. de 2 folios diferentes
Tipo C: 2 folios

Tipo F: 33 folios

Tipo I: 1 folio

El tipo de letra empleado por todos los escribanos moriscos es el llamado magrebí, con rasgos característicos como la i con el punto diacrítico debajo (ب) o la escrita con un único punto diacrítico (ف).

La mayoría de los documentos de los libros de cuentas están escritos por la mano del escriba morisco. Esto hace plantearse la cuestión de si es él mismo quien escribe también la parte en romance. En documentos como los legajos del 587-36 al 587-42, por ejemplo, son dos escribas diferentes para cada lengua: la lengua romance está en castellano mientras que la que está en árabe es un simple apartado a pie de página contrastando en un árabe resumido lo que en castellano se dice. Es en los legajos 587-51-56 donde está la duda. Por un lado 
se podría decir que es el mismo escriba, tanto para lengua romance como para lengua árabe, ya que se ve claramente que la relación de cuentas la lleva el escriba morisco, pues es la primera lengua que encontramos siempre, siendo la romance (la castellana o la valenciana) el apéndice de ésta. Sin embargo, al contrastar las informaciones dadas en cada una de las lenguas, se observa que no especifican exactamente lo mismo. Mientras que en lengua árabe siempre hay una relación "individuo - viaje (cuando lo hay) - trabajo realizado - símbolo o cifra numérica (cuando lo hay)", en lengua romance se encuentra reflejado lo mismo más el sueldo que vale dicho trabajo realizado y que lo expresa mediante palabras además de con cifras. Otras veces, es más la información aportada en el texto romance que en el árabe. Hay que puntualizar que los sueldos en la parte de escritura en árabe están dados con los signos numéricos aparecidos en dichas relaciones, mientras que en la parte escrita en castellano/valenciano, además de plasmar numéricamente el sueldo, también lo especifican mediante la palabra.

Del empleo de las tintas se pueden entresacar dos conclusiones que responden a las preguntas que se formulaban al comienzo de este apartado:

1 / que la mano del escriba sea, para la lengua árabe uno distinto que para la escritura de la parte castellana/valenciana;

2 / que sea la misma mano la que escribe en ambas lenguas. En ambos casos responde a una misma finalidad y es que, a golpe de vista, se pueda diferenciar lo escrito en cada lengua.

En el primer caso se tendría pues una doble contabilidad que la llevarían tanto el responsable de la aljama como el funcionario cristiano, mientras que en el segundo caso simplemente se vería una única contabilidad, la árabe, siendo la parte en romance la traducción o, mejor dicho, el contenido mismo de lo árabe pero de cara al funcionario cristiano para justificar los sueldos que se plasman en cifras, pues a la postre lo que cuenta es la suma de esas cifras. Respondiendo a la primera de las cuestiones establecidas, en los legajos del primer grupo lo importante es el texto en castellano (el escriba castellano, el baile Gabriel de Llanos), pues es lo que va destinado al propio señor, mientras que el apunte en árabe vale sólo como mera contabilidad para la aljama de que lo que se le dice al señor es cierto.

Es también notable la cantidad de escribanos que se encuentran a lo largo de todo el documento. C. Barceló diferencia en su tesis el uso del árabe en dos ámbitos: uno público y otro privado ${ }^{51}$. Es el uso privado el que aquí nos interesa. Lo que aquí interesa es si este uso privado se limitaba al empleo oral exclusivamente y el escrito estaba reservado a una élite de instruidos. En el documento que nos ocupa, tan limitado, destaca el hecho de tener 11 caligrafías, lo que equivale a 11 manos diferentes que saben, por lo menos, escribir en carac-

51. C. BARCEló TORRES, op. cit., pp. 138-143. 
teres árabes e, incluso, en lengua árabe. Se puede aventurar que si bien no todos tienen el mismo nivel ortográfico ni la misma cantidad de textos, sí que existe una mínima formación en la lengua árabe escrita que no sólo está destinada a una élite instruida. Es el caso de Juan Solas (escriba letra I), entre otros, que únicamente firma lo que cobra. Esto pone de relieve que sí había, por lo menos, una alfabetización entre la comunidad musulmana más alta de lo que se puede suponer en un principio ${ }^{52}$, no solo en el empleo oral de la lengua árabe, sino ya también escrita, lo que ofrece una idea sobre el índice de alfabetización de muchos moriscos, no tanto para poder escribir un texto completo pero si el suficiente nivel como para poder escribir sus propios nombres, en algunos casos utilizando hasta los signos de vocalización. Por lo tanto, este uso de la escritura para las firmas no responde a un nivel de conocimiento completo de la lengua árabe clásica, es decir, no se puede asegurar que todos los escribas pudieran escribir y leer al mismo nivel, ya que en algunas de las caligrafías sólo se encuentran en las firmas y no aparecerán nunca más en los demás legajos, mientras otros tipos de grafías sí se repiten en otros legajos y, en alguna ocasión, no sólo se limitan a la escritura del nombre-firma, sino que redactan texto en sí. Una apreciación que se extrae de entre todas las firmas y tipos de letras que se puede nominalizar es que ninguna de ellas pertenece a mujer.

Por lo tanto, no pueden traducirse estos ejemplos como la tesis de que todos y cada uno de los escribas supieran escribir y leer el texto árabe, pero sí se puede mantener que existe un cierto nivel de escritura, lo cual no implica saber leer un texto árabe dado ${ }^{53}$ ni tener una gran formación.

\section{TRASCRIPCIÓN POR ESCRITO DE LA LENGUA HABLADA: VALENCIANISMOS}

Como se ha venido diciendo a lo largo del presente artículo, se ha optado por no llamar "aljamiado" a la lengua escrita en árabe de los textos aparecidos en el documento OSUNA, C. 587, D. 36-65 del AHN, $\mathrm{SN}^{54}$, ya que no se trata de lengua romance escrita con grafía árabe, pero tampoco llega a ser completamente lengua árabe, ya que se mezclan demasiados aspectos romances en esta lengua, conjuntándose de esta manera las tres lenguas (árabe, castellano y valenciano) escritas con caracteres árabes. ¿Dónde termina el "préstamo lingüístico" por parte del romance al árabe y dónde empieza el "aljamiado" propiamente dicho? Para C. Barceló, a la hora de plantearse la aportación romance al árabe valenciano se

52. Ibídem, p. 141. Cfr. especialmente C. BARCELÓ y A. LABARTA, op. cit., p. 64 y ss.: "Esa alfabetización que daba acceso al Islam y permitía llevar una contabilidad o cartearse con otros estaba en manos de quienes la Inquisición llamó ‘alfaquíes'”.

53. M. PeÑA DíAZ, «El uso social de la escritura en Barcelona en el siglo XVI», Manuscrits, 11, 1993, pp. 143-168, concretamente las pp. 144-145.

54. Supra nota 29. 
deben considerar varias influencias distintas: "las aportaciones léxicas romances al árabe son [...] cultismos o extranjerismos, muchos de ellos adaptados al consonantismo semítico" ${ }^{55}$. Además, hay palabras árabes que el romance tomó prestadas de la lengua árabe para, posteriormente, volver a pasar al árabe ${ }^{56}$.

En el presente trabajo únicamente se ha querido dejar abierto este debate para, en futuros trabajos, poder centrarse en él de manera más precisa. Para ello baste decir que, en ciertos párrafos de los textos, tanto podría ser castellano/valenciano escrito en caracteres árabes, con algo de lengua árabe, como al revés, lengua árabe con castellano/valenciano escrito en caracteres árabes. Un ejemplo de esto lo tenemos en el lg. 587-55 f. 3 scc. 2, que es totalmente bilingüe, como puede verse en la página siguiente:

\section{L1. `Alí Alboi trajo losas al \\ L2. forn de Llombai y trajo}

L3. coses a la almàssera

\section{L4. Acarreó aceite al çeller y en-}

\section{L5. vasó aceite en el çeller}
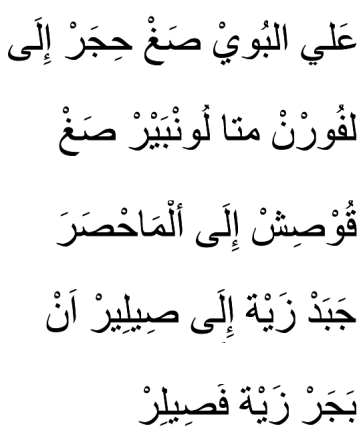

En este ejemplo se puede comprobar que la palabra almàssera ha sufrido una doble evolución. Pues la propia palabra árabe (المعصرة) primero pasa al valenciano (almàssera) y, posteriormente, es arabizada nuevamente (الماحصر ") . Una primera impresión lingüística podría parecer que el término podría ser castellano (almazara), pero es por su equivalente en valenciano (almàssera), debido a una casi segura imela en la vocal de la segunda radical de $\mathrm{A}>\mathrm{E}$, y el alargamiento de la primera vocal A con 'alif. De esta manera daría el vocablo almàssera. Posteriormente, esta palabra, convertida en un término valenciano, se reescribe con grafía árabe aunque modificada por la propia oralidad del valenciano, de ahí que sea الماحصرy no المعصرة.

El fenómeno en el que un término árabe deviene en un castellanismo/valencianismo, y este último, a su vez, vuelve a pasar al árabe totalmente transformado, sustituyendo al primero, es el que se da en casos como en ges ${ }^{57}$.

55. C. BARCELÓ TORRES, op. cit., p. 131.

56. Como el caso de almàssera. Cfr. A. LABARTA, «Algunos aspectos del dialecto árabe valenciano en el s. XV a la luz del fondo de documentos del AHN», Actas de las II jornadas de cultura árabe e islámicas (1980), Madrid, 1986, pp. 281-315, p. 308 y ss.

57. Cfr. Lg. 587-56, f. 2. 
Los préstamos árabes muestran una clara preponderancia de los sustantivos frente a los adjetivos, verbos y adverbios ${ }^{58}$. En la siguiente tabla se muestra una relación de los diferentes términos que se encuentran en los textos, de lengua castellana y valenciana (sobre todo, esta última), escritas con caracteres árabes, donde se puede observar lo anteriormente dicho:

\begin{tabular}{|c|c|c|c|c|c|c|c|c|c|c|c|c|c|c|c|}
\hline PALABRA/LEGAJO & 50 & 51 & 52 & 53 & 54 & 55 & 56 & 57 & 58 & 59 & 60 & 63 & 64 & 65 & $\mathrm{~T}^{59}$ \\
\hline Açebib/pasas ${ }^{60}$ & & & & & & & & & & & & & & 2 & 2 \\
\hline Albarà & & 3 & 6 & & 1 & 7 & 1 & & & & & & & 10 & 28 \\
\hline Almàssera & & 37 & 8 & & & 8 & 9 & 1 & & & & & & 13 & 76 \\
\hline Batlle & & 1 & 4 & & & & & 1 & & & & & & & 6 \\
\hline Capa & & & & & & & & & & & & & 1 & & 1 \\
\hline Çeller & & 3 & 2 & & & 8 & & & & & & & & 2 & 15 \\
\hline Cort & & & & & & & 1 & 1 & & & & & & & 2 \\
\hline Coses & 2 & & & & & 1 & & & & & & & & & 3 \\
\hline$D u c$ & & 6 & & & & 1 & & & & & & & & & 7 \\
\hline Embajador & & & & & & & 1 & & & & & & & & 1 \\
\hline Envasar & & & & & & 3 & 1 & & & & & & & & 4 \\
\hline Forn & 3 & & & 4 & 4 & 6 & & & & & & & & & 17 \\
\hline Ges & & & & & & & 1 & & & & & & & & 1 \\
\hline Governador & & 1 & & & & & & & & & & & & 3 & 4 \\
\hline Graner & & & & & & 1 & 1 & & & & & & & 3 & 5 \\
\hline Hostal & & 2 & & & & 22 & 3 & & & & & & & & 27 \\
\hline Iglesia & & & & & & & & & & & & & 1 & & 1 \\
\hline Joan Garsía & & 3 & 1 & & & 7 & 1 & & & & & & & 8 & 20 \\
\hline Jornal & 12 & & & & 8 & & & 1 & & & & & 1 & & 22 \\
\hline Lebrillos/Lebrel & & 2 & 1 & & & & & & & & & & & & 3 \\
\hline L'obra & & 1 & & & & & & & & & & & & & 1 \\
\hline Llibre & & & & & & 1 & & & & & & & & & 1 \\
\hline Marquès & & 3 & 7 & & 6 & & & & & & & & & 2 & 18 \\
\hline Palejar & & 3 & 1 & & & 1 & & & & & & & & 4 & 9 \\
\hline
\end{tabular}

58. C. BARCeló TORRES, op. cit., p. 273.

59. Total de veces aparecidas los términos a lo largo de todo el documento.

60. الزّبيب PASAS TC: Pansas. En valenciano: açebib (cfr. lg. 65, f. 1, scc. 6). 


\begin{tabular}{lrrrrrrrrrrrrrrr}
\hline PALABRA/LEGAJO & 50 & 51 & 52 & 53 & 54 & 55 & 56 & 57 & 58 & 59 & 60 & 63 & 64 & 65 & $\mathrm{~T}$ \\
\hline Plaça & & 1 & 1 & & & & & & & & & & & & 2 \\
Pòlissa & & & & & & & 1 & & 1 & 1 & 1 & 1 & & & 5 \\
Provisión & & 1 & & & & & & & & & & & & & $\mathbf{1}$ \\
Sèquia & 17 & 10 & & & 13 & 3 & 1 & & & & & & 9 & 57 \\
Tapieres & & & & & & & 1 & & & & & & & 3 & 4 \\
\hline Total & 17 & 84 & 41 & 4 & 19 & 79 & 24 & 5 & 1 & 1 & 1 & 1 & 3 & 59 & 339 \\
\hline
\end{tabular}

Como se puede comprobar en la tabla, sólo se encuentran dos verbos ( $\mathrm{pa}$ lejar y envasar) frente al resto de sustantivos. Se pueden dividir por grupos semánticos de la siguiente manera:

- Títulos: batlle, duc, embajador, governador, marquès.

- Lugares/edificios: almàssera, çeller, graner, forn, hostal, iglesia, cort, l'obra, plaça, sèquia.

- Técnico/comercial: albarà, pòlissa, jornal.

- Productos: Açebib, capa, coses, ges, lebrillos, llibre, provisión, tapieres.

- Nombres propios: Joan Garsía.

- Acciones: palejar, envasar.

Puede apreciarse en el siguiente listado que no aparece ninguna relación toponímica, pues se ha optado separar ésta del resto en un apartado específico que no será tratado en este artículo. Son un total de 29 préstamos lingüísticos.

En cuanto a los nombres que se encuentran computados a lo largo de todo el manuscrito, aparecen un total de 103 referentes personales, de los cuales 7 sólo hacen referencia al nombre propio (sin dar apellido) o al revés; y 3 hacen referencia a una situación personal (viudez). De esta manera, se tienen 95 nombres propios identificados y otros 7 localizados pero sin nombre. Las otras 7 referencias posiblemente se refieran a nombres aparecidos en otros textos de los mismos legajos, pero acortados.

En muchos casos es el nombre árabe y el nombre romance para la misma persona; y en algunos de estos no coincide, como en el caso de al-Qiëari, que en el texto romance aparece como Galvet. Hará falta un estudio minucioso futuro para establecer unas conclusiones más concretas acerca del cambio de nombre islámico a uno cristiano de la comunidad morisca de esta zona ${ }^{61}$, ya que, de

61. R. Pinilla Pérez de Tudela, «Crisis en las Germanías de Alzira a través de los impuestos reales (1500-1536)», III Assemblea d'Historia de la Ribera, Carcaixent, 1983, p. 126: "ya que se ha apuntado la teoría de que el nuevo convertido elige un nombre similar al que poseía anteriormente, que sea válido para las dos religiones y culturas, pero que no despierte suspicacia en las autoridades religiosas". 
momento, con los datos aportados sólo se puede intuir que en muchos casos podría ser el seudónimo por el que se les conocía a algunos de ellos, o es el nombre cristiano que se les daba o tomaban tras su "conversión" al cristianismo.

De toda la relación antroponímica, 16 apellidos están repetidos en varios individuos, tal vez miembros de un mismo núcleo familiar. Estos apellidos son: Adindin (2), Alboi (4), Baboni (2), Calep (5), Caranch (2), Cosari (2), Chiquillo (2), Gannet (6), Gonai (2), Guillem (2), Josai (3), Mandarani (2), Parell (3), Piletes (2), Pina (2), Podes (3) y Targuas (3).

También se encuentra un Mas `ud Algas y un Goso. Mientras que del primero se sabe el nombre, del segundo no se ofrece esa información y, a pesar de la diferencia en la escritura, se puede afirmar que es el mismo apellido, ya sea "Algas" o "Goso". Lo mismo ocurre con los nombre de Abrahim Apu y Apo: en el primero se da el nombre islámico mientras que en el segundo sólo se tiene el apellido y entre ambos apellidos la diferencia es tan sólo vocálica $(\mathrm{O}>$ U). Como se puede comprobar en la relación detallada en el cuadro de los nombres, en realidad hay 2 miembros con el apellido Piteu, mientras que en la relación de apellidos repetidos se han nombrado 3. Esto se debe a que se encuentra reflejado un apellido Beteu (de nombre Abrahim) y podría ser el mismo apellido: Beteu > Piteu. Por otro lado hay un Cosari y un Qiëari, apellidos que también se pueden poner en común y afirmar que son el mismo (sin embargo, en este caso, no se ha realizado su inclusión en el listado de apellidos repetidos, pues no se tiene en ningún caso un nombre al que relacionar dichos apellidos). Con el apellido Josai ocurre lo mismo que con el apellido Piteu: hay dos miembros nombrados con el apellido Josai y un individuo con el apellido Josei, diferencia vocálica que no se tiene en cuenta, por lo que se puede afirmar también en este caso que son el mismo apellido (por lo tanto, son 3 los individuos con este apellido). Los escribas también hablan de un Maimón y de un Abrahim Maimón: en el primer caso no se puede saber si se refiere al apellido o al nombre, al contrario que en el segundo caso, que sí se puede saber que es el apellido; no se mantiene que se refieran ni a la misma persona (en el caso de que el escriba haya omitido el nombre), ni que sea un nombre propio (ya que el escriba tampoco nos da el apellido) y tampoco que sea el mismo apellido (porque en este caso tampoco se da el nombre de dicho individuo). Con el apellido Sisi se puede decir que se encuentra documentado en fecha posterior, en 1607, en una mujer llamada María Sisi, "morisca de dieciocho años originaria de Tavernes" ${ }^{\prime 2}$. Por otro lado, no aparece referido más que un nombre de mujer (Salama), pero se dan tres referencias femeninas debidas a la condición jurídica de las mismas: la viuda de `Ali Axer y la viuda de Ahmad Gaugau. También se encuentra una viuda de Axer, que no se puede afirmar que sea la misma que la primera u otra persona diferente, ya que el escribano no da el nombre del marido fallecido. Y finalmente, también se refleja la condición de parentesco respecto del hijo de Sa`ad Gonai, del que tampoco se tiene el nombre.

62. Según cita en E. CísCAr PAllarés, op. cit., p. 143: ARV, Cl, caja 2.183, 11 de agosto de 1607. 
Antes de intentar dar datos sobre población morisca hay que decir que en ningún momento se ha perdido de vista que el contenido del documento OSUNA, C. 587, D. 36-65 del AHN, SN es principalmente de carácter laboral y, en menor medida, económico. Respecto del posible censo poblacional morisco de Llombai, no es fiable aventurar cifras al respecto, pues sólo se tiene en cuenta la relación antroponímica del libro de cuentas, a falta de contrastar estos datos con posibles fichas de partidas de nacimientos y / o bautismos debidos a las conversiones ${ }^{63}$, una relación que sólo especifica a un individuo concreto: mayor de edad, varón (aunque en varias ocasiones se cita una mujer) y en activo. Suponiendo que cada miembro nombrado fuera la cabeza visible de un marco familiar, a raíz de multiplicar 4 miembros por familia, y sabiendo que se da una relación de 118 nombres identificados, el censo poblacional morisco de Llombai rondaría los 500 individuos ${ }^{64}$.

Por lo tanto solo se puede decir claramente que el libro de cuentas refleja un censo escueto y, en gran medida, resbaladizo pues sólo se mencionan los jornaleros en unas fechas concretas al ser el reflejo de los trabajos realizados como pago de las tandas. A esto hay que añadir la escasez de fuentes al respecto sobre la época, que apenas aportan cifras significativas o exactas, que en palabras de C. Barceló sólo hay algunos datos referidos al siglo XV: “En opinión de Pérez Puchal $(1876,17)$, presenta la misma tendencia que Europa Occidental a un descenso general de la población" ${ }^{\prime 65}$. Sin embargo, para el siglo XVI se establecen dos etapas demográficas: la primera etapa abarcaría el período comprendido entre 1527 y 1563, en el que no se aprecia un aumento de la población espectacular (un 7\%); y un segundo período, que va desde 1563 hasta el momento mismo de la expulsión, donde hay un aumento demográfico importante $(69 \%)^{66}$. Por otro lado, hay datos que hablan de un descenso poblacional en las fechas previas al primer período, descenso demográfico provocado en su mayor parte por la guerra de las Germanías y por la conversión forzosa obligada por los agermanados ${ }^{67}$.

63. En septiembre del año 1525 se promulga la orden de conversión general al cristianismo de los mudéjares que vivían en los reinos de Valencia y Aragón, lugares en los que aún se transigía el derecho a ser musulmán (L. de P. MARTínez, «Actitud de la iglesia de Cartagena ante mudéjares y moriscos», Actas del III Simposio Internacional de Mudejarismo, Teruel, 20-22 de septiembre de 1984, Teruel, Instituto de Estudios Turolenses, 1986, p. 73). Esto conllevó al cierre de todas las mezquitas y a la salida de España de los musulmanes no convertidos, dando así por liquidado el estatuto de mudéjar.

64. Se podría estimar un número relativamente mayor al dado, pues el número de moriscos habitantes en Valencia fue abundante (L. de P. MARTínEZ, op. cit., p. 73).

65. C. BARceló TORRes, op. cit.

66. Ibídem, p. 63. Cita a Lapeyre, quien justifica estos datos "por la casi imposibilidad de emigrar y, mucho más importante para él, por la ausencia del celibato eclesiástico entre los musulmanes (1959, pp. 29-32)". Para más información, nos remitimos aquí al mismo trabajo de C. BARCELó TORRES, op. cit., pp. 64-70.

67. Ibídem, p. 69. 


\section{LA LENGUA DEL MANUSCRITO}

El estudio lingüístico de los manuscritos se puede resumir en los siguientes puntos.

1. La ausencia o desconocimiento por parte del autor de las reglas gramaticales ordinarias en árabe para el femenino de las palabras, ya que en la mayoría de los casos no utiliza la $t \bar{a}^{\prime}$ marbùt ț como marca de femenino al final de las palabras, siendo ésta sustituida por un alif o la marca de fatha sobre la última radical de la palabra que se quiere hacer en femenino.

2. Destacar el hecho o, mejor dicho, la ausencia total de sufijos y afijos en el árabe escrito: no se ha encontrado a lo largo de todo el documento ninguna marca sufijada o afijada, ni en verbos ni en sustantivos ni en ninguna otra palabra.

3. El escribano árabe se vale del conocimiento de las dos lenguas (en este caso podríamos decir que tres: árabe, castellano y valenciano), por lo que puede emplear el uso de eufemismos, como tenemos en el caso de la palabra vino.

4. El uso recurrente por parte de los escribanos de la perífrasis verbal, construida con los verbos مشى (como verbo auxiliar, siempre conjugado en $3^{a}$ persona del singular) + رأى (bajo la forma oralizada de وَرَ (sin preposición o conjunción de enlace) + la acción (bajo la forma de otro verbo en infinitivo). Esta construcción responde claramente a las perífrasis verbales en castellano "ir a ver de + acción", "haber de + infinitivo" o "ir a + infinitivo"; sobre todo es una construcción del habla común valenciana "vore de + infinitivo".

5. No se puede afirmar que prime la manera de construcción oracional latina clásica (donde el orden de los elementos es: sujeto, verbo, predicado), pero tampoco que lo haga el modo de construcción oracional del árabe clásico (verbo, sujeto, complementos). Sin embargo, sí es característico que cada sección se comience al modo latino, es decir, poniendo primero el sujeto (el nombre del individuo), seguido del verbo. A partir de ahí, se pueden extraer dos ideas: que las frases copulativas siguientes siguen la manera de construcción árabe (verbo seguido de sujeto y complementos); o, simplemente, se sigue prefiriendo el modo de construcción oracional latino y el escriba omite el sujeto porque ya se conoce.

6. Son numerosos los ejemplos que nos muestran una clara desaparición de la hamza s en el árabe escrito. Sin embargo, el escribano sí conoce su escritura, pues hace uso de la hamza por ejemplo a la hora de escribir los nombres de أحمد بر بر بر o de بر بر اءة >بر Pero ya no la escribe en palabras como. أبر هيم.

68. Esta palabra también aparece referida con este tipo de escritura en los textos estudiados por C. BARCELÓ TORRES, op. cit., p. 220 y ss.). El sentido que C. Barceló le da a la palabra árabe es albarán. Se ha mantenido en este trabajo este sentido semántico a pesar de que en los textos castellanos sólo se da el concepto de carta, nunca de albarán, concepto que diferencian claramente del concepto póliza, que viene dado con la palabra árabe بلصية. 
7. Se sustituye el uso de la id̂afa (إضافة) a favor de la construcción preposicional con Sólo se usa la construcción de iḍ̂afa cuando el escribano utiliza la construcción تسمية الجرنل . En todos los casos en los que se encuentra esta

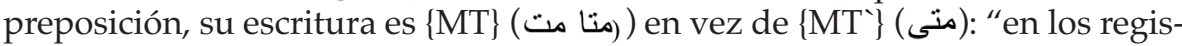
tros bajos del andalusí, sobre todo en caudas y en los casos en que su caída generaría diptongo, $/$ / podría desaparecer, como en $[\ldots]>$ matā $<\ll$ de» ${ }^{\prime 70}$.

8. Otro rasgo que se ha podido apreciar en los textos es el fenómeno de imela en el lenguaje hablado gracias a que los escribas han vocalizado la mayor parte de los textos, lo que da una aproximación al lenguaje árabe hablado. Un ejemplo claro es la preposición في : في : siempre cae la mientras que la ف se unirá a la siguiente palabra y su vocalización será en fatha (fenómeno de imela de I > A). En el legajo 587-52 hay un ejemplo de imela de A > I en la palabra ستة:

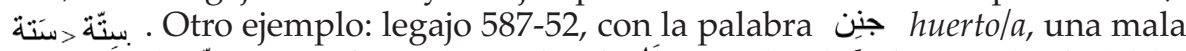

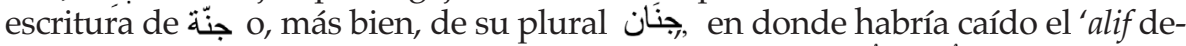
bido, posiblemente, a una imela de A > I. También en رُمَنْ > رَنَن.

9. Un recurso utilizado por los escribas es el uso de un artículo indefinido واحد. Para Corriente la existencia de este artículo indefinido es debido a la influencia del sustrato romance ${ }^{71}$.

10. Otra característica de los textos radica en el hecho de que los escribanos apenas utilizan los plurales de los sustantivos que nombran, es decir, utilizan simplemente el singular para referirse a un conjunto de cosas. Un ejemplo: la palabra تين (sg. higo) en vez de أثيان (pl. higos).

11. En el caso de palabras que en árabe tienen su correspondiente, se hace caso omiso de aquel omitiendo su uso y prefiriendo el término en castellano o valenciano escrito con grafía árabe. Palabras como "1'obra", "gobernador", "llibre"...

12. A lo largo de todo el documento se encuentra repetido infinidad de veces el término جرنل, جر انيل incluso su plural. Según el Diccionario de Lengua Española de la Real Academia" ${ }^{72}$ " JJornal > (Del prov. jornal, der. del lat. diurnus) 1. m. Estipendio que gana el trabajador por cada día de trabajo; 2. m. Este mismo trabajo; 3. m. Medida de tierra, de extensión varia, usada en diferentes provincias de España; 4. loc. adv. Mediante determinado salario cotidiano, a di-

69. F. CORRIENTE, Árabe andalusí y lenguas romances, Madrid, ed. Mapfre, 1992, p. 110: "Por lo que se refiere al sintagma rectivo [...] el andalusí posee recursos alternativos a la mera construcción de 'iḍāfa, de los que el más típico es / matá(')/".

70. Ibídem, p. 47.

71. F. Corriente, op. cit., p. 83. Cfr. A. CONSTÁn NAVA, La lengua árabe a través del manuscrito OSUNA, C. 587, D. 36-65 (1533 - 1539) del Archivo Histórico Nacional, Sección Nobleza: Traducción, estudio y aportaciones histórico-lingüísticas (en prensa), especialmente, lg. 587-51 f. 5 scc. 4; lg. 587-52 f. 2 scc. 3; lg. 587-52 f. 6 scc. 2; lg. 587-52 f. 6 scc. 4; lg. 587-57.

72. Real Academia Española, Diccionario de Lengua Española/Real Academia Española, Madrid, Espasa-Calpe, 1992, $21^{\text {a }}$ ed. 
ferencia del trabajo que se ajusta a destajo". Se sabe que existe el mismo término derivado de la palabra turca: جرنال (turco) pl. جرانيل ات periódico (sust.); revista" $^{\prime \prime 3}$. Pero la hipótesis en este caso hace inclinar su sentido por la primera acepción, es decir, sería una palabra derivada del castellano/valenciano debido a la influencia del sustrato romance sobre el andalusí. Mientras que el singular es claramente de origen latino, no ocurre así con su plural, que utiliza la flexión interna del árabe para formarse bajo la forma $\{\mathrm{CaCāCīL}\}$ : جرانيل porque "la integració d'un mot no-semític en el sistema de flexió interna d'una llengua semítica es dona si hi ha dues condicions: a) que la llengua estragera d'on prové el mot en qüestió siga prou coneguda encara que no dominant en un ambient monolingüe semític [...]; i, b) que no hi hagi un rebuig de la paraula no-semítica per una instància d'ortodòxia lingüística" ${ }^{17}$.

13. Una de las características más notables de los escribanos es que desconocen la escritura correcta en árabe clásico del nombre de Alläh اله cuando éste va referido o incluido en un antropónimo. Se puede comprobar cuando escribe el nombre de la persona que contabiliza: عبد الله > عبدلا (lg. 587-51 f. 6 scc. 3). Esto se debe más bien a que el escribano desconoce que el antropónimo tiene que ver con el propio nombre de Allăh: desconocimiento de la ortografía del antropónimo unido al desconocimiento de que el propio antropónimo tiene que ver con el nombre de Allāh. Lo mismo ocurre con el nombre de محمد que, aunque el error es la no escritura de la šadda, no se puede asegurar que no conozcan el uso de dicha marca pues la emplean en otros términos.

14. Como se ha venido diciendo a lo largo del presente trabajo, el fenómeno de la escritura como trascripción de la lengua oral es una de las características más sobresalientes del texto, lo que se podría llamar "oralidad en la escritura"75 (uno de los ejemplos entre tantos otros se encuentra en el legajo

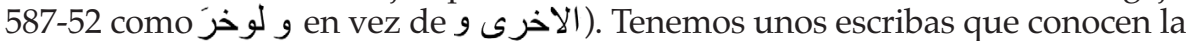
lengua árabe hablada ${ }^{76} \mathrm{y}$, al mismo tiempo, conocen la escritura árabe ${ }^{77}$, pero

73. J. Contés, Diccionario de árabe culto moderno. Árabe-Español, Madrid, ed. Gredos, 1996, p. 167.

74. M. DE EPALZA, «Diminutiu amb flexió interna àrab en cognoms catalans: "curt", "cureyet" (Concentaina, 1515)», A Sol Post, 1990, p. 137.

75. Esta definición, que en sí parece una antítesis, no es más que una mera adecuación terminológica para poder referirse a esa funcionalidad de los propios escribanos de intentar plasmar mediante la escritura aquella lengua que escuchan diariamente: una escritura basada en una previa y escasa formación en lengua árabe clásica, sobre todo a nivel escrito. Es decir, intentan plasmar mediante grafía los sonidos de la lengua árabe dialectal de la zona valenciana que utilizan y escuchan diariamente, una lengua plasmada bajo unos escasos rudimentos de la lengua árabe clásica. Los numerosos ejemplos vistos hasta el momento dan fe de esta idea, idea que se refuerza cuando, a través de la visualización de un mismo término escrito, lo vemos plasmado de varias formas diferentes por la mano de un mismo escribano (o diferente). Cfr. A. LABARTA, op. cit., p. 287.

76. C. BARCELÓ TORRES, «Lengua árabe y lengua catalana: intercambios bajo medievales», El Islam y Cataluña, Barcelona, Institut Català de la Mediterrània, 1998.

77. Conocen el alifato y sus alófonos tanto en lengua árabe como sus correspondientes en lengua castellana y valenciana. 
desconocen las reglas de ortografía de la lengua árabe clásica. Es este último caso el que lleva a pensar que:

1/ El árabe como lengua se está perdiendo, dando paso a una cada vez más fuerte lengua dominante como el castellano y el valenciano, lo que nos indica una clara desarabización de la comunidad musulmana o, por lo menos, una clara desarabización escrita;

2 / La poca formación de los escribas árabes la acusan a la hora de escribir en árabe (como ya se ha venido desarrollando en el apartado correspondiente a la lengua).

3 / Ya no prima el carácter lingüístico de la lengua, sino el informativo: el escriba sólo quiere transmitir una información a aquellos que sepan leerla, por lo que prima el canal informativo respecto del formal lingüístico (el escriba no es un literato por lo que no debe guardar las formas del lenguaje). En relación a este punto, se puede observar una especie de "comodidad" lingüística por parte de los escribas que no prestan atención a cómo escriben: simplemente escriben y no se fijan si una misma palabra escrita dos veces lo hacen de distinta manera, pues para ellos sólo prima que la información llegue a un posible lector posterior o, simplemente, sea una información para él a la hora de defender los sueldos de los miembros de la comunidad pues sería él quien tendría que informar sobre los mismos al funcionario cristiano (lo importante es la "anotación" no la ortografía).

15. Al contrario de lo que ocurre con la escritura aljamiada, donde la cuestión religiosa aparece como un nudo fundamental a la hora de plantear el vertido de realidades árabe-islámicas en una lengua no árabe, en estos textos no se encuentra esa voluntad, pues no se está una realidad escrita aljamiada, por lo que los escribanos no tratan de transmitir esa realidad lingüística intentando que no pierda su connotación islámica. No existe esa voluntad de islamizar los términos, al revés de lo que ocurre con los textos aljamiados de carácter religioso $^{78}$, sino que los escribanos sólo tratan de informar, no buscar un mínimo canon lingüístico.

\section{LOS SISTEMAS DE REPRESENTACIÓN DE LAS CIFRAS Y NÚMEROS EN LOS TEXTOS}

Para finalizar el estudio, no se ha querido acabarlo sin antes desarrollar un pequeño análisis sobre las cifras y los números que aparecen a lo largo de todo el documento ${ }^{79}$. Al ser un libro de cuentas, es normal que en los textos apa-

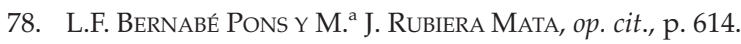

79. Cfr. C. Barceló y A. Labarta, op. cit., p. 47 y ss. 
rezcan símbolos numéricos para referirse a los pagos o cobros, siendo la suma la única expresión aritmética utilizada. En este caso, se puede decir que el 80\% de los legajos poseen cifras o cantidades. Además, en algunos de ellos aparecen referidos los años, pero esta vez, nunca mediante símbolo numérico sino que se limitan a escribirlo en palabras: es el caso del legajo 587-50, donde el escriba anota: عم اربعة و ثلثنة "año (15)34", dando siempre la fecha no musulmana.

Son 3 los tipos de símbolos y / o números:

a. En primer lugar, tenemos la numeración mediante cifra simbólica, que aparece en el margen derecho o izquierdo del texto árabe.

Ejemplos:

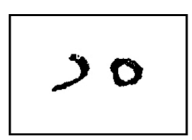

\section{0}

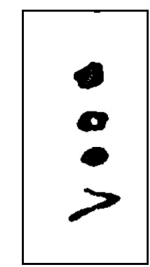

b. En segundo lugar, tenemos la numeración mediante los números romanos. Estos, al igual que las cifras, aparecen en el margen derecho o izquierdo inferior del texto romance.

Ejemplos:

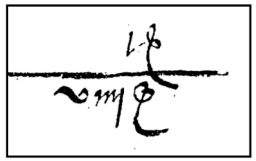

Ejemplo 1

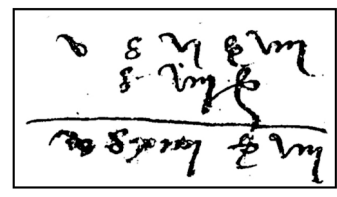

Ejemplo 2

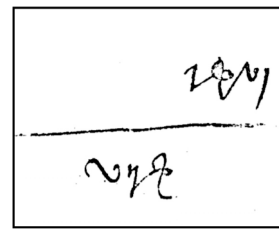

Ejemplo 3

c. En tercer lugar, tenemos la cifra numérica.

Ejemplos:

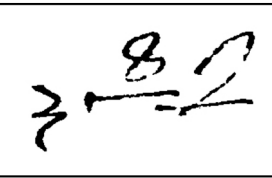

Ejemplo 4

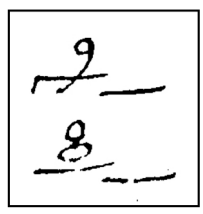

Ejemplo 5 
Estos números y cifras se corresponden con unas metrologías y unos sistemas monetarios concretos.

Sobre las "monedas de cuenta" 80 , se refieren claramente a la moneda de cuenta de la Corona de Aragón, que se basaba en la libra, que a su vez se dividía en 20 sueldos y, estos a su vez, se dividían en 12 dineros cada uno. Se puede observar en los ejemplos correspondientes a la cifra numérica, en los que el escriba utiliza estos valores trazando rayas debajo de las cifras correspondientes a los sueldos y dineros ${ }^{81}$.

De este modo, en el ejemplo $₹, \underline{2} 2,2$, significa “ 3 libras, 8 sueldos y 7 dineros", mientras que en el otro ejemplo se encuentran dos líneas distintas que se corresponden con "9 sueldos" y "8 sueldos".

Estas cifras, conocidas como notación gubāri ${ }^{82}$, aparecen para expresar cantidades de monedas en cuentas, nunca para expresar la fecha que se expresa mediante palabras. En todos los casos, esta fecha enunciada con palabras se da citándose sólo la unidad y la decena, nunca la centena ni la unidad de millar del año. Así, cuando dice ثنلثة و خمسة se refiere al 1535, dando siempre la fecha cristiana.

Las cifras gubāríes que se hayan plasmadas a lo largo de todos los documentos son:

\begin{tabular}{c|c|c|c|c|c|c|c|c|c}
1 & 2 & 3 & 4 & 5 & 6 & 7 & 8 & 9 & 0 \\
\hline 1 & $: 2$ & -3 & - & 5 & 6 & 2 & $g$ & 9 & -
\end{tabular}

El otro sistema utilizado es el rumí ${ }^{83}$, el más extendido en los textos. En este caso, utiliza como símbolos lo siguiente:

\section{0}

De este sistema, las equivalencias que se proponen se basan en la comparación de las cifras rumíes con las latinas, así como con la comparación con la propia descripción que en el TC se da del sueldo. De este modo, en el caso del símbolo "> " se puede afirmar que equivale a $1 / 2$, mientras que el símbolo "o"

80. A. LABARTA y C. BARCEló, Números y cifras en los documentos arábigohispanos, Córdoba, Universidad de Córdoba, 1988. p. 13: "Las Monedas de cuentas son sistemas teóricos que simplifican los cálculos y valoraciones".

81. Ibídem, p. 13.

82. Ibidem, pp. 37-46.

83. Ibídem, p. 22. 
equivale a 1. Estos símbolos se leerían de arriba a abajo (cuando estén escritos verticalmente), o de derecha a izquierda (cuando estén en horizontal). Por lo tanto, >o sería $1 \frac{1}{2}$, mientras que $\$$ sería $3 \frac{1}{2^{84}}$.

En la numeración romana separan las libras de los sueldos mediante este símbolo: $\mathcal{E}$; y los sueldos de los dineros mediante el siguiente símbolo: $\boldsymbol{\xi}$. Cuando las letras se juntan con los números, el escriba opta por dibujar una raya entre ambos, para que no exista ninguna confusión (véase el siguiente ejemplo):

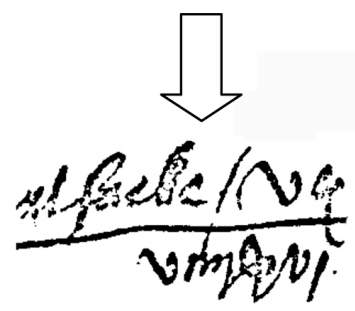

El contable ${ }^{85}$ es capaz de entender los tres sistemas numéricos: no se limita a las cifras latinas, sino que en la mayoría de los documentos utiliza dos de los tres sistemas (rumí/latino o gubārí/latino) indicados al margen de los textos o párrafos.

El que se escriban al margen de los textos es ejemplo de que al contable sólo le basta un golpe de vista para saber lo que está contando, sin tener que recurrir al texto en cuestión. Esto, simplemente, da rapidez a la hora de realizar el cómputo contable.

Por lo tanto, se puede afirmar que es un libro de cuentas o, más bien, un libro de apunte previo donde se especifican un control de gastos, siempre referidos estos gastos a los sueldos o jornales que los trabajadores realizan en compensación de tandas, ya que nunca se refiere a los precios que estos trabajadores pagan por los productos que adquieren, como la cal, los higos, etc.

\section{CONCLUSIONES}

Todo lo dicho hasta ahora se resume en la tesis de la poca formación que los escribas árabes acusan a la hora de escribir en árabe, al mismo tiempo que se observa esa, cada vez más acusada, desarabización escrita por parte de la comunidad musulmana, en favor de las lenguas dominantes, tanto el castellano

84. Ibídem, p. 34. En este caso, decimos que difiere de lo estipulado por Ana Labarta y Carmen Barceló en su libro, donde > sería 5 y ${ }^{\circ}$ sería 10.

85. Tanto el contable-escriba de la comunidad morisca como el de la universidad cristiana. 
como el valenciano. Lo que conduce al aspecto más controvertido de todo el trabajo y, también, el más arriesgado, que es pensar que existe en estos textos una especie de árabe andalusí cargado de préstamos del adstrato lingüístico castellano/valenciano, que hacen de esta lengua un punto intermedio entre el árabe andalusí escrito y la lengua aljamiada de los moriscos: no se trata de lengua romance escrita con grafía árabe, pero tampoco llega a ser completamente lengua árabe, ya que se ha comprobado que se mezclan demasiados aspectos romances en la lengua árabe escrita del documento, uniéndose de esta manera las tres lenguas (castellano, valenciano y árabe) escritas con caracteres árabes. Y no se puede reducir el concepto de préstamo lingüístico en este documento únicamente a aquellos conceptos que toma la lengua árabe dialectal respecto del castellano y del valenciano que luego plasma el escriba morisco con grafía árabe, puesto que se ha observado que hay otras aportaciones que no tienen nada que ver con simples términos, como lo son las construcciones oracionales propias de lenguas latinas o la adecuación de fórmulas o perífrasis verbales castellano-valencianas a la lengua árabe.

Además, se ve en este intento de escritura lo que se señaló anteriormente como el intento por parte de los escribanos de transmitir simplemente una información puntual, sin buscar un mínimo canon lingüístico, pues prima la idea que el posible lector entienda el mensaje que se le lanza y no que el lector se instruya a partir de los textos: el escriba sólo quiere transmitir una información a aquellos que sepan leerla, por lo que, como se apuntó anteriormente, prima el canal informativo respecto del formal lingüístico (el escriba no es un literato por lo que no debe guardar las formas del lenguaje). En relación a este punto, es posible observar una especie de "comodidad" lingüística por parte de los escribas que no prestan atención a cómo escriben: simplemente escriben y no se fijan si una misma palabra escrita dos veces lo hace de distinta manera, pues para ellos sólo prima que la información llegue a un posible lector posterior o, simplemente, sea una información para él a la hora de defender los sueldos de los miembros de la comunidad, pues sería él quien tendría que informar sobre los mismos al funcionario cristiano (lo importante es la "anotación" no la ortografía).

Esta segunda idea es la que hace aventurar que no son unos textos aljamiados, pues los escribanos no tratan de transmitir una realidad lingüística, intentando que no se pierda la connotación islámica en la escritura, al contrario que en la escritura aljamiada, donde la cuestión religiosa aparece como un nudo fundamental a la hora de plantear el vertido de realidades árabe-islámicas en una lengua no árabe.

Por otro lado, a pesar de insistir en la escasa formación de los escribanos, también hemos de señalar que si más bien la instrucción que reciben en lengua clásica árabe es muy limitada, la realidad muestra que utilizan esta herramienta rudimentaria de manera eficiente, pues consiguen su objetivo: informar. Además, conocen tres sistemas de representación de cifras y números y recurren a su escritura de manera indiferente, primando siempre la numeración romana junto con la gubārí o la rumí. Dichas cifras las colocan de manera que 
sean éstas, y no el propio texto árabe, lo fundamental de los legajos: lo importante es la cifra, que sea ésta lo que llame la atención visualmente, ya que a la postre es lo que interesa al ser un libro de cuentas o relación remunerada de tandas, siendo el texto, tanto árabe como castellano/valenciano, el apéndice o resumen a modo de nota de la propia cifra.

Finalmente, los textos han servido para abrir un pequeño campo de investigación sobre la realidad lingüística, social y económica de una comunidad morisca enmarcada en el Marquesado de Llombai, unas características que no se pueden extrapolar a todos los moriscos que conformaran la comunidad musulmana que habitaba en dicho lugar entre los años 1533 y 1539, pues lo que en estos textos se muestra es sólo un pequeño ejemplo de lengua árabe, muy limitada en cuanto a producción, pues es un libro de cuentas, y en cuanto a la propia realidad lingüística de dicha comunidad, ya que únicamente es posible caracterizar con estos ejemplos no la lengua hablada de la totalidad de la comunidad morisca sino la realidad lingüística de los escribanos.

\section{RESUMEN}

Traducción al español, estudio y aportaciones histórico-lingüísticas de los textos en árabe del manuscrito Osuna, C. 587, D. 36-65. Son textos de carácter contable que reflejan una relación de jornales trabajados en concepto de tandas por los moriscos de Llombai, Alfarp, Aledua y Catadau para su señor el duque de Gandía, entre los años 1533 y 1539.

Palabras clave: Marquesado de Llombai (Valencia), lengua árabe andalusí, moriscos, relación de jornales, tandas, siglo XVI.

\section{ABSTRACT}

Spanish translation, study and historical, linguistical contributions about some texts in arabic of the manuscript Osuna, C. 587, D. 36-65. They are a texts of an accounting nature that reflect a relationship of wages worked in concept of "tanda" for the moors of Llombai, Alfarp, Aledua and Catadau for mr el Duque Gandía, between the years 1533 and 1539.

Key words: Marquesado of Llombai (Valencia), Andalusian arabic language, Moriscs, a wages relationship, tandas, 16th Century. 